Geront. clin. 1965;7:82

\title{
Concours 1965
}

La Fondation Commemorative Dr Heinz Karger récompensera d'un prix en espèces, le meilleur travail sur le theme suivant:

PROBLÈMES MICROANGIOLOGIQUES DE L'ARTÉRIOSCLÉROSE

Ce prix est fixe à fr.s. 3000.-. Le Conseil de Fondation se prononcera sur le choix du travail et de Tattribution du prix.

Conditions

Langue: Anglais, allemand ou français.

Volume du manuscrit: Ce dernier ne devra pas dépasser 20 pages dactylo-graphiées, figures, tableaux et listes de references y compris. Le manuscrit est à écrire en double exemplaire et sur un côté seulement de chaque feuille; Гintervalle employe entre les lignes doit être double. Le manuscrit devra être rédigé conformément à nos «Directives sur la Redaction d'un Manuscrit et ГEtablissement d'une Bibliographie» (la brochure peut être obtenue gratuitement auprès de la Maison d'éditions, à condition que la demande porte la mention «pour le concours»). Délai: Les travaux seront à remettre à la Maison d'éditions, S. Karger S.A., Arnold-Böcklin-Strasse 25, à 4000 Bale 11 (Suisse), jusqu'au 31 août 1965 et devront porter la remarque suivante: «pour le concours». Publication: Le travail recompense sera publié en 1965, dans une des revues de la Maison d'éditions Karger. 